\title{
A Retrospective Comparative Study of Two Concentrations of Intralesional Triamcinolone Acetonide in the Treatment of Patchy Alopecia Areata on the Scalp
}

This article was published in the following Dove Press journal:

Clinical, Cosmetic and Investigational Dermatology

\author{
Jihan M Muhaidat (ID) \\ Firas Al-Qarqaz $\mathbb{D}^{1}$ \\ Yousef Khader $\mathbb{I D}^{2}$ \\ Diala M Alshiyab $\mathbb{D}^{\prime}$ \\ Hadeel Alkofahi' \\ Mohanad Almalekh' \\ 'Department of Dermatology, Faculty of \\ Medicine, Jordan University of Science \\ and Technology, Irbid, Jordan; \\ ${ }^{2}$ Department of Public Health, \\ Community Medicine, Jordan University \\ of Science and Technology, Irbid, Jordan
}

Correspondence: Jihan M Muhaidat Department of Dermatology, Faculty of Medicine, Jordan University of Science and Technology, Irbid 22110, Jordan Tel +96227200600

Fax +96227200624

Email jmmuhaidat@just.edu.jo
Background: Alopecia areata (AA) usually manifests as patches of non-scarring hair loss due to immune dysregulation. Intradermal injection of steroids is considered a first-line treatment of patchy AA.

Purpose: To compare the efficacy and safety of two commonly used concentrations of intralesional triamcinolone acetonide (ILT) $(5 \mathrm{mg} / \mathrm{mL}$ vs $10 \mathrm{mg} / \mathrm{mL})$ in the treatment of patchy AA on the scalp.

Patients and Methods: A retrospective comparative study that included 85 patients diagnosed with patchy AA on the scalp, who were treated with monthly injections of ILT. Patients were divided into Group 1 that received $5 \mathrm{mg} / \mathrm{mL}$ and Group 2 that received $10 \mathrm{mg} /$ $\mathrm{mL}$. The response rate (defined as the percentage of patients who achieved complete hair regrowth) and the side effects were compared between the two groups after completion of three treatment sessions, and recurrence was assessed after 1-3 years.

Results: Demographic composition of the two groups was comparable. The difference in response rate and the side-effects between the two groups were not statistically significant. Complete hair regrowth was noted in $43.5 \%$ of patients in Group 1 and $53.8 \%$ of those in Group 2 $(P=0.340)$. About $17 \%$ and $25 \%$ of patients in Group 1 and Group 2, respectively, developed minor local side-effects $(P=0.354)$, and almost $45 \%$ of patients from both groups had recurrence after 1-3 years. Disease duration exceeding 6 months correlated with poor treatment response. Conclusion: Intralesional injection of triamcinolone acetonide $5 \mathrm{mg} / \mathrm{mL}$ is equally effective and safe compared to $10 \mathrm{mg} / \mathrm{mL}$ in the treatment of patchy alopecia areata.

Keywords: alopecia areata, intralesional steroids, triamcinolone acetonide

\section{Introduction}

Alopecia areata (AA) is an autoimmune inflammatory disease of the hair follicles, and to a lesser extent the nails, leading to non-scarring patches of hair loss, mainly on the scalp, though any hair-bearing skin can be affected. As a part of the disease process, $T$ lymphocytes surround the anagen hair follicle bulb, a site that is normally immune privileged, causing the arrest of hair shaft growth, while the hair follicle itself is preserved. ${ }^{1-3}$ Genetic predisposition was revealed by a genome-wide association study that linked 139 single nucleotide polymorphism to AA. ${ }^{4}$ Environmental factors, including stress, infections, vaccinations, and diet, have less proven impact on the induction or exacerbation of the disease. ${ }^{5}$ 
AA is common and has no gender or race predilection, lifetime incidence is estimated at about $2 \%$ worldwide. ${ }^{6,7}$ Although the course of the disease is unpredictable, patients with first patch/patches of short duration have favorable outcome with good chances of spontaneous hair regrowth within 1 year. Almost all patients may experience recurrence, and $14-25 \%$ of patients may progress to extensive disease with complete scalp or body hair loss. ${ }^{8,9}$ While AA does not undermine general health, patients with AA have decreased coping abilities, which increase the prevalence of depression and anxiety among them. ${ }^{10,11}$

Various treatment options are available that should be tailored to disease severity and extent, as well as the psychological impact on the patient. Unfortunately, no treatment is curative or preventive. ${ }^{12-14}$

Intralesional steroids, usually triamcinolone acetonide (TA) in $2.5-10 \mathrm{mg} / \mathrm{mL}$ doses, are traditionally among the first treatment options for AA in adults. They are not FDA approved for this indication, but guidelines based on a literature review advocate their use for limited patchy cases. Intralesional triamcinolone acetonide (ILT) treatment generally involves injecting $0.1 \mathrm{~mL}$ of the diluted steroid with a 30 -gauge needle into the deep dermis at $1 \mathrm{~cm}$ intervals, while not exceeding $20 \mathrm{mg}$ ILT in a single session. Subsequent sessions should be scheduled 4-6 weeks apart, terminating treatment after 6 months if no response is achieved. ${ }^{1,-12-16}$ Given that 5 and $10 \mathrm{mg} / \mathrm{mL}$ are the most frequently used concentrations, ${ }^{17-21}$ the aim of this study was to compare the efficacy and safety of these two ILT concentrations in the treatment of patchy AA on the scalp.

\section{Patients and Methods Study Design and Patients}

This retrospective comparative study was conducted at the Dermatology Clinic of King Abdullah University Hospital, Irbid, Jordan. The study was approved by the Institutional Review Board at Jordan University of Science and Technology (IRB number 2018/219) and was conducted in accordance with the principles of the Declaration of Helsinki.

Patients were enrolled in this study if they had been diagnosed clinically and/or histologically with AA between June 2016 and January 2019, and were subsequently treated with ILT, specific inclusion criteria were: patients of all ages with patchy AA on the scalp that involved less than $50 \%$ of scalp surface area, who were treated by monthly injection of triamcinolone acetonide $5 \mathrm{mg} / \mathrm{mL}$ or $10 \mathrm{mg} / \mathrm{mL}$. Patients with extensive scalp involvement (surface area $>50 \%$, alopecia totalis or universalis), and those on combination therapy were excluded. While individuals exhibiting AA patches on both scalp and extra scalp sites (eg, beard, moustache, eye brows) were included, assessment was only performed on the scalp patches. All patients or their guardians provided informed consent to be included in the study.

Patients were divided into two groups based on the ILT concentration they received, whereby 46 patients treated with ILT $5 \mathrm{mg} / \mathrm{mL}$ were assigned to Group 1, and Group 2 was comprised of 39 patients who received ILT $10 \mathrm{mg} /$ $\mathrm{mL}$. Patients' electronic medical records and the serial photographs (if available) were reviewed. The data abstracted from medical records included demographic characteristics (age, gender), AA characteristics (duration, number of patches, scalp surface area affected, nail and extra scalp involvement), and medical history (past history of AA, atopy, comorbidities, and family history of AA).

For all patients, ILT was done on a monthly basis, whereby the steroids diluted with lidocaine or normal saline were injected using a 30-gauge needle at $1 \mathrm{~cm}$ intervals, starting from the periphery of the patch and moving toward its center, approximately $0.1-0.2 \mathrm{~mL}$ was injected per site.

Treatment response and the side-effects were recorded prior to the second and third treatment, and assessment for recurrence was performed 1-3 years after the last injection, either during the follow-up visit or over the phone.

\section{Outcome}

Response to treatment was assessed prior to the second and third injection sessions using the hair regrowth scale RGS (0-4) as follows: 0: $<10 \%$ regrowth, 1: $11-25 \%$ regrowth, 2: $26-50 \%$ regrowth, 3: 51-75\% regrowth, 4 : $\geq 75 \%$ regrowth. ${ }^{20}$ Comparison between the two groups for satisfactory hair regrowth (RGS 3 and 4) was done after up to three sessions.

The secondary outcomes included the frequency of side-effects such as atrophy, telangiectasia, folliculitis, and hypopigmentation, and the rate of AA recurrence or persistence after $1-3$ years.

\section{Statistical Analysis}

Statistical analysis was performed using IBM SPSS software version 24 (IBM SPSS Statistics, Armonk, NY). Chi- 
squared test was used to compare proportions between the two study groups. Multivariate analysis was conducted to determine the difference in the response rate between the two groups after adjusting for relevant clinical variables. Odds ratios were calculated using logistic regression. A $P$-value $<0.05$ was considered statistically significant.

\section{Results}

This study involved 85 patients (43 females and 42 males) with a total of 281 AA patches. Their age ranged from 5-66 years, with a mean (SD) age of 24 (12.9) years. Group 1 (46 patients with 157 patches) received ILT in $5 \mathrm{mg} / \mathrm{mL}$ concentration and Group 2 (39 patients with 124 patches) received ILT in $10 \mathrm{mg} / \mathrm{mL}$ concentration. The demographics and clinical characteristics of the two groups were generally comparable, as illustrated in Table 1.

The overall response rate to treatment (defined as a percentage of patients who achieved complete hair regrowth after up to three monthly injections) from both groups was 48\% (41/85). About 43.5\% (20/46) and 53.8\% $(21 / 39)$ of patients in Group $1(5 \mathrm{mg} / \mathrm{mL})$ and Group 2 (10 $\mathrm{mg} / \mathrm{mL}$ ) achieved complete regrowth (RGS 4) $(P=0.340)$. Moreover, 43\% (9/21) and 25\% (5/20) of Group 2 and Group 1, respectively, had complete hair regrowth after the first injection $(P=0.032)$. Figure 1 shows clinical photos of patients with variable RGS grades, and a patient with an overall RGS 4 (based on multiple patches) after one ILT $10 \mathrm{mg} / \mathrm{mL}$ injection is shown in Figure 2.

The difference in RGS (3 and 4) between the two groups was not statistically significant. The percentage of patients who achieved satisfactory outcome at 12 weeks (hair RGS 3 or 4 ) was 63\% (29/46) in Group 1 vs $76.9 \%$ $(30 / 39)$ in Group $2(P=0.166)$. About $70 \%(59 / 85)$ of this cohort achieved satisfactory outcome at 12 weeks.

The ILT side-effects documented by the treating physicians (also shown in serial photographs) were local and minor. Skin atrophy was the dominant side-effect; it was seen in $89 \%(16 / 18)$ of patients who developed sideeffects from both groups. Figure 3 shows skin atrophy at ILT injection sites (indicated by arrows). The rate of occurrence of these side-effects did not differ significantly between the two groups, as $17.4 \%(8 / 46)$ of patients who received ILT $5 \mathrm{mg} / \mathrm{mL}$ and $25.6 \%$ (10/39) of those who received ILT $10 \mathrm{mg} / \mathrm{mL}$ experienced these adverse outcomes $(P=0.354)$.
The rate of AA recurrence, assessed 1-3 years after the patients completed the treatment, was nearly equal for both groups; 45.7\% (21/46) and 46.2\% (18/39) for Group 1 and 2 , respectively $(P=0.963)$. Table 2 summarizes the outcome in both treatment groups.

Multivariate analysis revealed that the difference in the outcome between the two groups (measured as the percentage of patients with complete hair regrowth, percentage of patients with satisfactory outcome, and rate of AA recurrence) was not statistically significant. Of all studied variables, only disease duration was significantly associated with complete hair regrowth and satisfactory outcome $(P=0.029)$. Having the disease for more than 6 months was significantly associated with decreased odds of complete hair regrowth $(\mathrm{OR}=0.1,95 \% \quad \mathrm{CI}=0.1-0.7)$ and decreased odds of satisfactory outcome $(\mathrm{OR}=0.2,95 \%$ $\mathrm{CI}=0.1-0.9)$ when compared to a disease duration of less than 3 months. Multivariate analysis results are shown in Table 3.

It should be noted that $25.8 \%(22 / 85)$ of the study cohort had comorbidities, the most common of which was hypothyroidism $(31.8 \%, 7 / 22)$, followed by low ferritin (4/22), diabetes mellitus (3/22), hypertension $(2 / 22)$, vitiligo (2/22), psoriasis $(1 / 22)$, anxiety (1/22), depression $(1 / 22)$, and juvenile rheumatoid arthritis $(1 / 22)$.

\section{Discussion}

Our study involved two groups of patients that were similar in their demographic and clinical features. The findings suggest that the two most commonly used concentrations of ILT ( 5 and $10 \mathrm{mg} / \mathrm{mL}$ ) in the treatment of patchy AA on the scalp, could be considered equally effective at 12 weeks. However, ILT $10 \mathrm{mg} / \mathrm{mL}$ induced faster results and was superior at 4 weeks.

Literature review revealed only a few studies that mainly addressed the efficacy of different concentrations of ILT in the treatment of patchy AA, they were of different methodologies and their results were incongruent. An intrapilot study conducted on four patients revealed that three ILT concentrations $(2.5 \mathrm{mg} / \mathrm{mL}, 5 \mathrm{mg} / \mathrm{mL}, 10 \mathrm{mg}$ / $\mathrm{mL}$ ) were equally effective and were superior to normal saline. ${ }^{21}$ Another retrospective study involving 15 patients demonstrated that response to ILT is concentration dependent, but the findings were not statistically significant. ${ }^{22}$ A more recent study based on a systematic review and meta-analysis of seven previous studies indicated that $5 \mathrm{mg} / \mathrm{mL}$ and $10 \mathrm{mg} / \mathrm{mL}$ were equally effective. However, the authors noted inconsistencies between the 
Table I Demographic and Clinical Features of Patients in Treatment Groups

\begin{tabular}{|c|c|c|c|c|c|}
\hline & \multicolumn{2}{|c|}{$\begin{array}{l}\text { Group I ILT: } \\
5 \mathrm{mg} / \mathrm{mL} \\
(\mathrm{N}=46)\end{array}$} & \multicolumn{2}{|c|}{$\begin{array}{l}\text { Group } 2 \text { ILT: } \\
10 \mathrm{mg} / \mathrm{mL} \\
(\mathrm{N}=39)\end{array}$} & \multirow[t]{2}{*}{$P$-value } \\
\hline & $\mathbf{n}$ & $\%$ & $\mathbf{n}$ & $\%$ & \\
\hline \multicolumn{6}{|l|}{ Gender } \\
\hline Female & 21 & 45.7 & 17 & 56.4 & 0.323 \\
\hline Male & 25 & 54.3 & 22 & 43.6 & \\
\hline \multicolumn{6}{|l|}{ Age } \\
\hline Mean (SD) (years) & $20.9(\mathrm{II})$ & & $27.8(14)$ & & \\
\hline$\leq 18$ & 17 & 37.0 & II & 28.2 & 0.333 \\
\hline $19-30$ & 21 & 45.7 & 16 & 41.0 & \\
\hline$>30$ & 8 & 17.4 & 12 & 30.8 & \\
\hline \multicolumn{6}{|l|}{ Duration of treated AA patches } \\
\hline Mean (SD) (months) & $13.6(27)$ & & $10.5(17)$ & & 0.933 \\
\hline$\leq 2$ & 16 & 34.8 & 15 & 38.5 & \\
\hline $3-6$ & 13 & 28.3 & 10 & 25.6 & \\
\hline$>6$ & 17 & 37.0 & 14 & 35.9 & \\
\hline \multicolumn{6}{|l|}{ Number of patches } \\
\hline Mean (SD) & $3.4(4.2)$ & & $3.1(3.7)$ & & 0.652 \\
\hline 1 & 16 & 34.8 & 17 & 43.6 & \\
\hline 2 & 14 & 30.4 & 9 & 23.1 & \\
\hline$\geq 3$ & 16 & 34.8 & 13 & 33.3 & \\
\hline \multicolumn{6}{|l|}{ Scalp surface area affected $\%$} \\
\hline Mean (SD) & $5.4(5.2)$ & & $5.3(5.4)$ & & 0.858 \\
\hline$<3$ & 14 & 30.4 & 14 & 35.9 & \\
\hline $3-5$ & 16 & 34.8 & 12 & 30.8 & \\
\hline $6+$ & 16 & 34.8 & 13 & 33.3 & \\
\hline Past history of AA & II & 23.9 & 11 & 28.2 & 0.653 \\
\hline Personal history of atopy (atopic dermatitis, asthma, allergic rhinitis) & 13 & 28.3 & 9 & 23.1 & 0.587 \\
\hline $\begin{array}{l}\text { Comorbidities (hypothyroidism, low ferritin, hypertension, diabetes mellitus, } \\
\text { juvenile rheumatoid arthritis, vitiligo, psoriasis, depression, anxiety) }\end{array}$ & 13 & 28.3 & 9 & 23.1 & 0.587 \\
\hline Nail involvement (fine pitting, trachyonychia, leuconychia) & 4 & 8.7 & 2 & 5.1 & 0.522 \\
\hline Extra scalp sites (eyebrow, moustache, legs, beard) & 10 & 21.7 & 7 & 17.9 & 0.663 \\
\hline Family history of AA & 6 & 13 & 7 & 17.9 & 0.536 \\
\hline
\end{tabular}

studies included in the review regarding the primary outcome measured, technique, frequency, and duration of treatment, as well as the availability of demographics and clinical features. $^{23}$

On the other hand, a randomized controlled trial had shown that ILT $10 \mathrm{mg} / \mathrm{mL}$ was more effective than ILT $5 \mathrm{mg} / \mathrm{mL}$, which in turn was more effective than ILT $2.5 \mathrm{mg} / \mathrm{mL}$. Cutaneous side -effects were more frequently seen with ILT $10 \mathrm{mg} / \mathrm{mL}$. However, in this study, the number of patches on the scalp was relatively small; 20 patches were treated with ILT $10 \mathrm{mg} / \mathrm{mL}$, compared to 17 patches treated with ILT $5 \mathrm{mg} / \mathrm{mL}$, and patients were not followed-up beyond 6 months. ${ }^{24}$

ILT safety was amply demonstrated in this study, as only minor and local side-effects (atrophy, telangiectasia, folliculitis, dyspigmentation) were observed. Their frequency was slightly higher in the ILT $10 \mathrm{mg} / \mathrm{mL}$ group, but the difference did not reach statistical significance.

The results yielded by the present study indicate a good response to ILT treatment, as $48 \%$ of patients from both groups achieved complete hair regrowth and $70 \%$ experienced satisfactory results after 1-3 injections. The adverse 
A

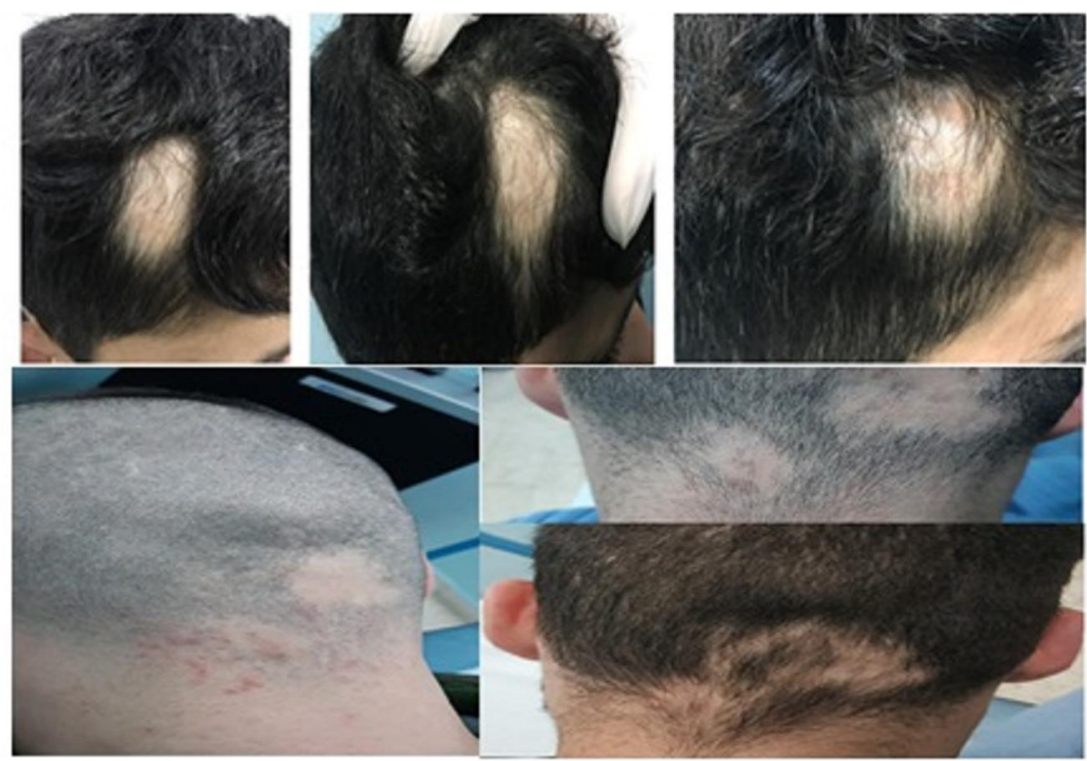

C

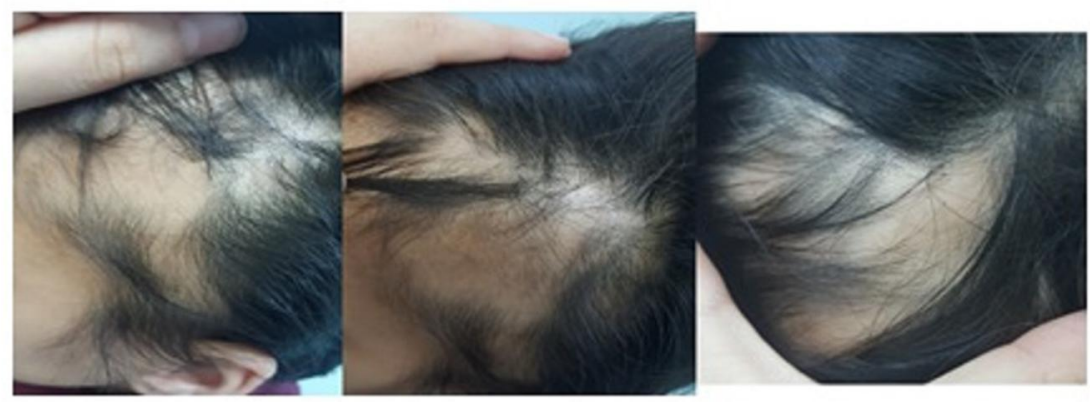

D

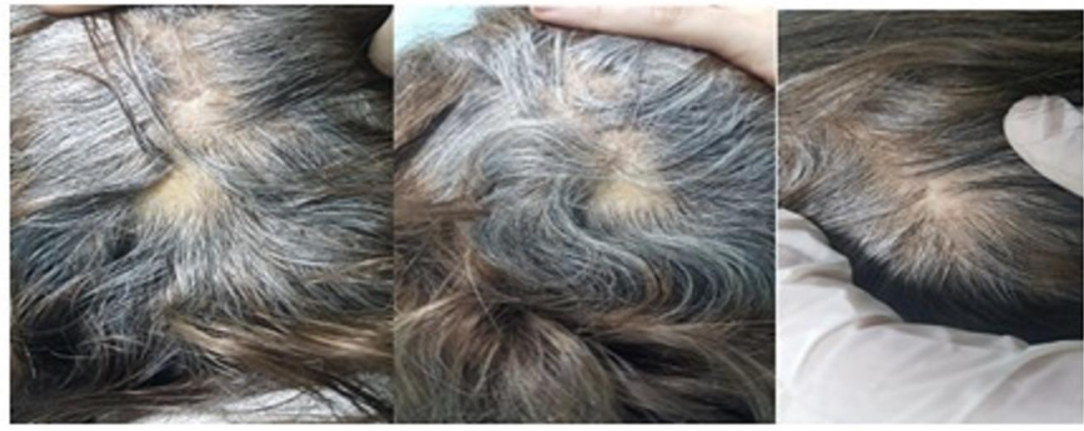

E

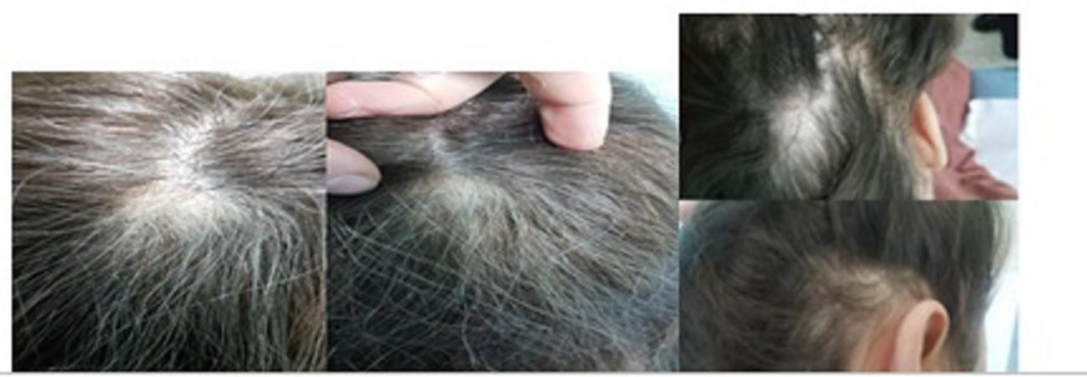

Figure I Clinical pictures of patients with various hair regrowth scale (RGS), (A) RGS 0 (<10\%), (B) RGS I (II-25\%), (C) RGS 2 (26-50\%), (D) RGS 3 (5I-75\%), (E) RGS 4 $(>75 \%)$. 


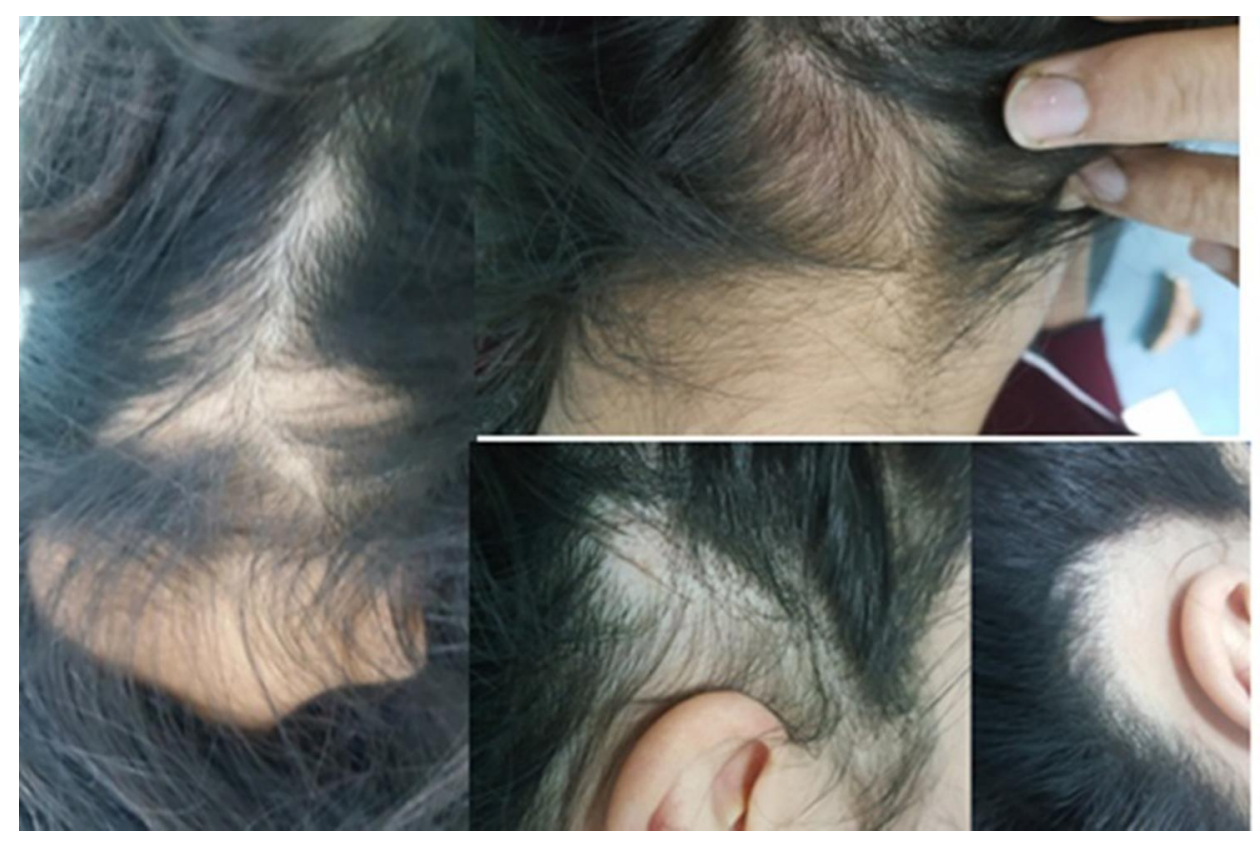

Figure 2 A patient with occipital and temporal patches showing complete hair regrowth after single injection of ILTI0 mg/mL.

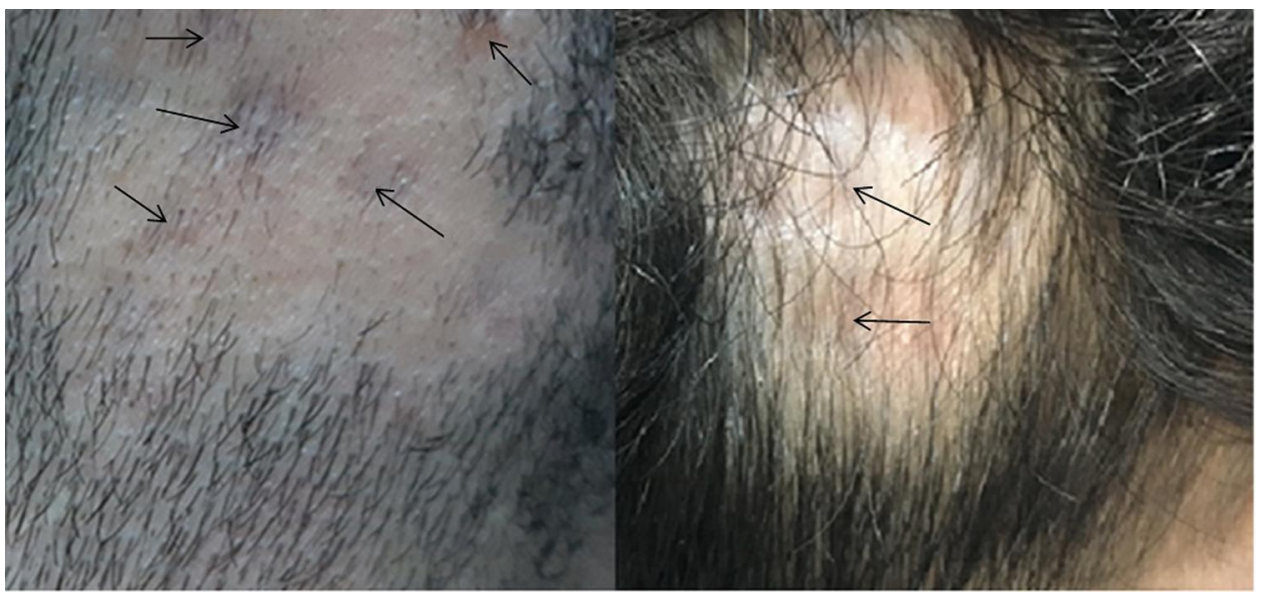

Figure 3 Skin atrophy observed at sites of ILT injection (arrows).

impact of a longer disease duration ( $>6$ months) was shown, suggesting that early treatment may increase the chance of a favorable outcome. This is in line with a previous study that found longer AA duration was associated with lack of response to both topical and intralesional corticosteroid regimens. ${ }^{25}$

Our findings further indicate that almost half of AA patients will experience recurrence, irrespective of the ILT dose. Moreover, none of the prognostic variables studied was correlated with long-term recurrence (after 1-3 years), making this aspect of AA highly unpredictable. Whether patients receiving systemic treatment (eg, immunosuppressive modalities) have less recurrence should be evaluated in future studies.

Common associations of AA with autoimmune diseases were demonstrated in this study. Although most patients were known to have these disorders at presentation, some were only revealed by investigations or during follow-up. For example, hypothyroidism affected seven patients, three of whom were diagnosed by screening performed at baseline. Additionally, a young female that was successfully treated for her patchy AA was found on follow-up to have juvenile rheumatoid arthritis, and similar sequential associations were reported. ${ }^{26,27}$ Thus, 
Table 2 Inter-Group Comparison of Response to Treatment

\begin{tabular}{|c|c|c|c|c|c|}
\hline & \multicolumn{2}{|c|}{$\begin{array}{l}\text { Group I: ILT } 5 \mathrm{mg} / \mathrm{mL} \\
(\mathrm{N}=46)\end{array}$} & \multicolumn{2}{|c|}{$\begin{array}{l}\text { Group 2: ILT } 10 \mathrm{mg} / \mathrm{mL} \\
(\mathrm{N}=39)\end{array}$} & \multirow[t]{2}{*}{$P$-value } \\
\hline & $\mathbf{n} / \mathbf{N}$ & $\%$ & $\mathbf{n} / \mathbf{N}$ & $\%$ & \\
\hline Patients with complete hair regrowth or hair RGS of 4 at 12 weeks & $20 / 46$ & 43.5 & $21 / 39$ & 53.8 & 0.340 \\
\hline Patients with satisfactory outcome at 12 weeks (hair RGS 4 or 3 ) & $29 / 46$ & 63 & $30 / 39$ & 76.9 & 0.166 \\
\hline Overall side-effects & $8 / 46$ & 17.4 & $10 / 39$ & 25.6 & 0.354 \\
\hline Atrophy & $5 / 46$ & 10.8 & $6 / 39$ & 15.3 & \\
\hline Atrophy and telangiectasia & $2 / 46$ & 4.3 & $3 / 39$ & 7.6 & \\
\hline Folliculitis & $\mathrm{I} / 46$ & 2.1 & $0 / 39$ & 0 & \\
\hline Hypopigmentation & $0 / 46$ & 0 & $1 / 39$ & 2.5 & \\
\hline Recurrence after $I-3$ years of follow-up & $21 / 46$ & 45.7 & $18 / 39$ & 46.2 & 0.963 \\
\hline
\end{tabular}

Table 3 Results of Multivariate Analysis

\begin{tabular}{|c|c|c|c|c|c|c|c|c|c|c|c|c|}
\hline \multirow[b]{3}{*}{ ILT conc. (10 mg/mL vs $5 \mathrm{mg} / \mathrm{mL}$ ) } & \multicolumn{4}{|c|}{$\begin{array}{l}\text { Rate of Complete Hair } \\
\text { Regrowth }\end{array}$} & \multicolumn{4}{|c|}{$\begin{array}{l}\text { Percentage of Patients with } \\
\text { Satisfactory Outcome }\end{array}$} & \multicolumn{4}{|c|}{$\begin{array}{l}\text { Recurrence of AA After I-3 } \\
\text { Years of Follow-Up }\end{array}$} \\
\hline & \multirow{2}{*}{$\frac{\text { OR }}{1.6}$} & \multicolumn{2}{|c|}{$95 \% \mathrm{Cl}$} & \multirow{2}{*}{$\begin{array}{l}P \text {-value } \\
0.307\end{array}$} & \multirow{2}{*}{$\begin{array}{l}\text { OR } \\
2.0\end{array}$} & \multicolumn{2}{|c|}{ Cl $95 \%$} & \multirow{2}{*}{$\begin{array}{l}P \text {-value } \\
0.221\end{array}$} & \multirow{2}{*}{$\frac{\text { OR }}{1.0}$} & \multicolumn{2}{|c|}{ Cl $95 \%$} & \multirow{2}{*}{$\frac{P \text {-value }}{0.946}$} \\
\hline & & 0.6 & 4.9 & & & 0.7 & 5.8 & & & 0.4 & 2.6 & \\
\hline Gender (Male vs Female) & 0.8 & 0.2 & 2.7 & 0.756 & 0.7 & 0.2 & 2.4 & 0.538 & 0.7 & 0.2 & 2.5 & 0.617 \\
\hline Personal history of AA (Yes vs No) & 3.1 & 0.8 & 11.7 & 0.090 & 1.3 & 0.4 & 4.8 & 0.663 & 0.5 & 0.2 & 1.8 & 0.331 \\
\hline Atopy (Yes vs No) & 1.2 & 0.3 & 4.1 & 0.790 & 0.5 & 0.1 & 1.8 & 0.297 & 1.3 & 0.4 & 4.4 & 0.713 \\
\hline Comorbidities (Yes vs No) & 0.7 & 0.2 & 2.5 & 0.579 & 1.2 & 0.3 & 4.2 & 0.787 & 1.0 & 0.3 & 3.5 & 0.978 \\
\hline Nail involvement (Yes vs No) & 2.2 & 0.2 & 23.0 & 0.517 & 1.1 & 0.1 & 11.5 & 0.907 & 2.2 & 0.2 & 23.0 & 0.796 \\
\hline Extra scalp sites (Yes vs No) & 2.1 & 0.5 & 9.4 & 0.351 & $\mathrm{I} .4$ & 0.3 & 5.9 & 0.663 & 2.8 & 0.7 & 12.3 & 0.163 \\
\hline Age (years) & - & - & - & 0.699 & - & - & - & 0.724 & - & - & - & 0.043 \\
\hline$\leq 18$ & - & - & - & - & - & - & - & - & - & - & - & - \\
\hline $19-30$ & 1.6 & 0.5 & 5.5 & 0.422 & 1.0 & 0.3 & 3.5 & 0.989 & 0.5 & 0.2 & 1.7 & 0.294 \\
\hline$>30$ & 1.4 & 0.3 & 6.0 & 0.664 & 0.6 & 0.1 & 2.6 & 0.464 & 3.0 & 0.7 & 12.3 & 0.126 \\
\hline Duration (months) & - & - & - & 0.093 & - & - & - & 0.135 & - & - & - & 0.358 \\
\hline$\leq 2$ & - & - & - & - & - & - & - & - & - & - & - & - \\
\hline $3-6$ & 0.4 & 0.1 & 1.8 & 0.260 & 0.4 & 0.1 & 1.7 & 0.224 & 0.7 & 0.2 & 2.8 & 0.638 \\
\hline$>6$ & 0.2 & 0.0 & 0.9 & 0.029 & 0.2 & 0.1 & 1.0 & 0.045 & 1.9 & 0.5 & 6.9 & 0.333 \\
\hline Number of patches & - & - & - & 0.833 & - & - & & 0.977 & - & - & - & \\
\hline I & - & - & - & - & - & - & - & - & - & - & - & - \\
\hline 2 & I.I & 0.2 & 6.1 & 0.905 & 1.2 & 0.2 & 7.4 & 0.867 & 1.7 & 0.3 & 8.8 & 0.556 \\
\hline$\geq 3$ & 0.7 & 0.1 & 4.4 & 0.718 & 1.2 & 0.2 & 8.7 & 0.828 & 1.6 & 0.3 & 10.7 & 0.608 \\
\hline Surface area affected\% & - & - & - & 0.371 & - & - & - & 0.371 & - & - & - & 0.685 \\
\hline$<3$ & - & - & - & - & - & - & - & - & - & - & - & - \\
\hline $3-5$ & 3.2 & 0.7 & 14.8 & 0.140 & 0.5 & 0.1 & 2.5 & 0.363 & 1.6 & 0.3 & 6.9 & 0.564 \\
\hline$\geq 6$ & 0.6 & 0.1 & 3.7 & 0.577 & 0.2 & 0.0 & 1.8 & 0.162 & 0.9 & 0.1 & 6.1 & 0.935 \\
\hline Family history of AA (yes vs No) & 0.7 & 0.1 & 3.5 & 0.664 & 0.2 & 0.3 & 4.2 & 0.528 & 1.7 & 0.3 & 3.8 & 0.983 \\
\hline
\end{tabular}

Abbreviations: $\mathrm{OR}$, odds ratio; $\mathrm{Cl}$, confidence interval.

regular screening of patients with AA for associated autoimmune diseases is advocated, and vigilance about any underlying disorders is recommended.

Our results provide further support for a comparable efficacy of the two concentrations, which has implications for both patients and treating physicians. Using the $5 \mathrm{mg}$ / $\mathrm{mL}$ concentration compared to $10 \mathrm{mg} / \mathrm{mL}$ would double the injection volume, allowing a wider surface area to be covered without exceeding the maximal recommended dose per session. This is important for limiting the 
patients' exposure to the systemic and local side-effects of steroids. A study comparing even lower concentrations of ILT (eg, $2.5 \mathrm{mg} / \mathrm{mL}$ vs $5 \mathrm{mg} / \mathrm{mL}$ ) would be a very important addition to this body of research. Actually, a recent study has illustrated the comparable efficacy of various corticosteroid regimens (topical, intralesional, or their combination) in the treatment of focal AA. ${ }^{25}$

Although this study has limitations related to its retrospective design, it included a relatively large number of patients (85 patients divided into two groups) with 281 patches on the scalp (157 vs 124 for $5 \mathrm{mg} / \mathrm{mL}$ and $10 \mathrm{mg}$ / $\mathrm{mL}$, respectively). Moreover, the patients were thoroughly compared regarding their clinical characteristics and the prognostic factors. We have also followed the patients for 1-3 years to assess the long-term treatment outcome.

\section{Conclusion}

This study showed that, in the treatment of patchy alopecia areata of the scalp, intralesional triamcinolone at 5 or $10 \mathrm{mg} / \mathrm{mL}$ concentration was equally effective in achieving satisfactory hair regrowth. The side -effects were slightly more common in the $10 \mathrm{mg} / \mathrm{mL}$ group; however, the difference was not statistically significant. Around half of the patients will have recurrence after 1-3 years, regardless of the treatment received or their prognostic factors, and longer disease duration ( $>6$ months) has a negative impact on response to treatment.

\section{Funding}

This study was approved and supported by the Deanship of Research at the Jordan University of Science and Technology.

\section{Disclosure}

The authors report no conflicts of interest in this work.

\section{References}

1. Perera E, Yip L, Sinclair R. Alopecia areata. In: Alopecias-Practical Evaluation and Management. Vol. 47. Karger Publishers; 2015:67-75.

2. Gilhar A. Collapse of immune privilege in alopecia areata: coincidental or substantial? J Invest Dermatol. 2010;130:2535-2537. doi:10.1038/jid.2010.260

3. Islam N, Leung PS, Huntley AC, Gershwin ME. The autoimmune basis of alopecia areata: a comprehensive review. Autoimmun Rev. 2015;14(2):81-89. doi:10.1016/j.autrev.2014.10.014

4. Petukhova L, Duvic M, Hordinsky M, et al. Genome-wide association study in alopecia areata implicates both innate and adaptive immunity. Nature. 2010;466(7302):113-117. doi:10.1038/nature09114
5. Darwin E, Hirt PA, Fertig R, Doliner B, Delcanto G, Jimenez JJ. Alopecia areata: review of epidemiology, clinical features, pathogenesis, and new treatment options. Int J Trichology. 2018;10(2):51. doi:10.4103/ijt.ijt_99_17

6. Safavi K. Prevalence of alopecia areata in the First National Health and Nutrition Examination Survey. Arch Dermatol. 1992;128:702. doi:10.1001/archderm.1992.01680150136027

7. Fricke AC, Miteva M. Epidemiology and burden of alopecia areata: a systematic review. Clin Cosmet Investig Dermatol. 2015;8:397.

8. Messenger AG, McKillop J, Farrant P, et al. British Association of Dermatologists' guidelines for the management of alopecia areata 2012. Br J Dermatol. 2012;166(5):916-926. doi:10.1111/j.13652133.2012.10955.x

9. Pratt $\mathrm{CH}$, King LE, Messenger AG, Christiano AM, Sundberg JP. Alopecia areata. Nat Rev Dis Primers. 2017;3(1):1-7. doi:10.1038/ nrdp.2017.11

10. Rodgers AR. Why finding a treatment for alopecia areata is important: a multifaceted perspective. J Investig Dermatol Symp Proc. 2018;19(1):S51-S53. Elsevier. doi:10.1016/j.jisp.2017.10.008

11. Aghaei S, Saki N, Daneshmand E, Kardeh B. Prevalence of psychological disorders in patients with alopecia areata in comparison with normal subjects. Int Sch Res Notices. 2014;2014.

12. Alkhalifah A, Alsantali A, Wang E, McElwee KJ, Shapiro J. Alopecia areata update: part II. Treatment. J Am Acad Dermatol. 2010;62(2):191-202. doi:10.1016/j.jaad.2009.10.031

13. Shapiro J. Current treatment of alopecia areata. J Investig Dermatol Symp Proc. 2013;16(1):S42-S44. Elsevier. doi:10.1038/jidsymp.2013.14

14. Lee S, Lee WS. Management of alopecia areata: updates and algorithmic approach. J Dermatol. 2017;44(11):1199-1211. doi:10.1111/ 1346-8138.13933

15. Kassim JM, Shipman AR, Szczecinska W, et al. How effective is intralesional injection of triamcinolone acetonide compared with topical treatments in inducing and maintaining hair growth in patients with alopecia areata? A critically appraised topic. $\mathrm{Br} J$ Dermatol. 2014;170(4):766-771. doi:10.1111/bjd. 12863

16. Gupta AK, Carviel J, Abramovits W. Treating alopecia areata: current practices versus new directions. Am J Clin Dermatol. 2017;18 (1):67-75. doi:10.1007/s40257-016-0230-4

17. Abell E, Munro DD. Intralesional treatment of alopecia areatawith triamcinolone acetonide by jet injector. $\mathrm{Br} J$ Dermatol. 1973;88:55-59. doi:10.1111/j.1365-2133.1973.tb06672.x

18. Kubeyinje EP. Intralesional triamcinolone acetonide in alopecia areata amongst 62 Saudi Arabs. East Afr Med J. 1994;71:674-675.

19. Devi M, Rashid A, Ghafoor R. Intralesional triamcinolone acetonide versus topical betamethasone valearate in the management of localized alopecia areata. J Coll Physicians Surg Pak. 2015;25 (12):860-862.

20. Kuldeep CM, Singhal H, Khare AK, Mittal A, Gupta LK, Garg A. Randomized comparison of topical betamethasone valerate foam, intralesional triamcinolone acetonide and tacrolimus ointment in management of localized alopecia areata. Int J Trichology. 2011;3 (1):20. doi:10.4103/0974-7753.82123

21. Chu TW, AlJasser M, Alharbi A, Abahussein O, McElwee K, Shapiro J. Benefit of different concentrations of intralesional triamcinolone acetonide in alopecia areata: an intrasubject pilot study. $J \mathrm{Am}$ Acad Dermatol. 2015;73(2):338-340. doi:10.1016/j.jaad.2015.04.049

22. Stallings AM. ILK index and regrowth in alopecia areata. $J$ Investig Dermatol Symp Proc. 2015;17:47-49. doi:10.1038/jidsymp.2015.27

23. Yee BE, Tong Y, Goldenberg A, Hata T. Efficacy of different concentrations of intralesional triamcinolone acetonide for alopecia areata: A systematic review and meta-analysis. $J$ Am Acad Dermatol. 2020;82(4):1018-1021. doi:10.1016/j.jaad.2019.11.066

24. Ustuner P, Balevi A, Özdemir M. Best dilution of the best corticosteroid for intralesional injection in the treatment of localized alopecia areata in adults. J Dermatol Treat. 2017;28(8):753-761. doi:10.1080/ 09546634.2017 .1329497 
25. Suchonwanit P, Kositkuljorn C, Mahasaksiri T, Leerunyakul K A comparison of the efficacy and tolerability of three corticosteroid treatment regimens in patients with alopecia areata. $J$ Dermatol Treat. 2020:1-21.

26. Forouzan P, Cohen PR. Systemic lupus erythematosus presenting as alopecia areata. Cureus. 2020;12(6).
27. Forouzan P, Cohen PR. Incipient diabetes mellitus and nascent thyroid disease presenting as beard alopecia areata: case report and treatment review of alopecia areata of the beard. Cureus. 2020;12(7).

\section{Publish your work in this journal}

Clinical, Cosmetic and Investigational Dermatology is an international, peer-reviewed, open access, online journal that focuses on the latest clinical and experimental research in all aspects of skin disease and cosmetic interventions. This journal is indexed on CAS.
The manuscript management system is completely online and includes a very quick and fair peer-review system, which is all easy to use. Visit http://www.dovepress.com/testimonials.php to read real quotes from published authors. 